\title{
EQUIVALENT STATEMENTS OF A MORE ACCURATE EXTENDED MULHOLLAND'S INEQUALITY WITH A BEST POSSIBLE CONSTANT FACTOR
}

\author{
Bicheng Yang, Meifa HuAng ANd YANRU Zhong
}

\begin{abstract}
By the use of the weight functions, the idea of introduced parameters and HermiteHadamard's inequality, a more accurate extended Mulholland's inequality and its equivalent form are given. A few equivalent statements of the best possible constant factor related to some parameters, some particular cases and the operator expressions are considered.
\end{abstract}

Mathematics subject classification (2010): 26D15.

Keywords and phrases: Weight function, Mulholland's inequality, equivalent statement, Hermite-Hadamard's inequality, operator expression.

\section{REFERENCES}

[1] G. H. Hardy, J. E. Littlewood, G. Pólya, Inequalities, Cambridge University Press, Cambridge, 1934.

[2] B. C. YANG, The norm of operator and Hilbert-type inequalities, Science Press, Beijing, China, 2009.

[3] B. C. YANG, Hilbert-Type Integral Inequalities, Bentham Science Publishers Ltd., The United Arab Emirates, 2009.

[4] B. HE, A multiple Hilbert-type discrete inequality with a new kernel and best possible constant factor, Journal of Mathematical Analysis and Applications, 431(2015), 990-902.

[5] J. S. XU, Hardy-Hilbert's inequalities with two parameters, Advances in Mathematics, 36(2)(2007), 63-76.

[6] Q. L. HuAnG, A new extension of Hardy-Hilbert-type inequality, Journal of Inequalities and Applications (2015), 2015:397.

[7] Z. T. XIE, Z. ZENG, Y. F. SUN, A new Hilbert-type inequality with the homogeneous kernel of degree -2, Advances and Applications in Mathematical Sciences, 12(7)(2013), 391-401.

[8] Z. Zeng, K. Raja Rama Gandhi, Z. T. XIE, A new Hilbert-type inequality with the homogeneous kernel of degree -2 and with the integral, Bulletin of Mathematical Sciences and Applications, 3(1)(2014), 11-20.

[9] D. M. XIN, A Hilbert-type integral inequality with the homogeneous kernel of zero degree, Mathematical Theory and Applications, 30(2)(2010), 70-74.

[10] L. E. AZAR, The connection between Hilbert and Hardy inequalities, Journal of Inequalities and Applications, 2013:452, 2013.

[11] B. C. YANG, Q. CHEN, A more accurate multidimensional Hardy-Mulholland-type inequality with a general homogeneous kernel, Journal of Mathematical Inequalities, 12(1)(2018), 113-128.

[12] M. TH. RASSIAS, B. C. YANG, On an equivalent property of a reverse Hilbert-type integral inequality related to the extended Hurwitz-zeta function, Journal of Mathematics Inequalities, 13(2)(2019), 315334.

[13] V. Adiyasuren, T. BAtBold, M. Krnić, Hilbert-type inequalities involving differential operators, the best constants and applications, Math. Inequal. Appl., 18(1)(2015), 111-124.

[14] M. Krnić, M. Z. GaO, J. PeČArić, X. M. GaO, On the best constant in Hilbert's inequality, Math. Inequal. Appl. 8(2)(2005), 317-329.

[15] M. KRnić, J. PEČARIĆ, Extension of Hilbert's inequality, J. Math. Anal. Appl., 324(2006), 150-160. 
[16] M. KRnić, A refined discrete Hilbert inequality via the Hermite-Hadamard inequality, Comput. Math. Appl, 63 (2012), 1587-1596.

[17] M. TH. RASSiAs, B. C. YANG, On half-discrete Hilbert's inequality, Applied Mathematics and Computation, 220(2013), 75-93.

[18] B. C. YANG, M. KRnIĆ, A half-discrete Hilbert-type inequality with a general homogeneous kernel of degree 0, Journal of Mathematical Inequalities, 6(3)(2012), 401-417.

[19] M. TH. RAssias, B. C. YANG, A multidimensional half-discrete Hilbert-type inequality and the Riemann zeta function, Applied Mathematics and Computation, 225 (2013), 263-277.

[20] M. TH. RASSiAS, B. C. YANG, On a multidimensional half-discrete Hilbert-type inequality related to the hyperbolic cotangent function, Applied Mathematics and Computation, 242(2013), 800-813.

[21] Z. X. HUANG, B. C. YANG, On a half-discrete Hilbert-type inequality similar to Mulholland's inequality, Journal of Inequalities and Applications, 2013:290, 2013.

[22] B. C. YAng, L. Debnath, Half-Discrete Hilbert-Type Inequalities, World Scientific Publishing, Singapore, 2014.

[23] Y. Hong, Y. Wen, A necessary and Sufficient condition of that Hilbert type series inequality with homogeneous kernel has the best constant factor, Annals Mathematica, 37A(3)(2016), 329-336.

[24] Y. HonG, On the structure character of Hilbert's type integral inequality with homogeneous kernel and applications, Journal of Jilin University (Science Edition), 55(2)(2017), 189-194.

[25] Y. Hong, Q. L. HuAnG, B. C. YANG, J. L. LiaO, The necessary and sufficient conditions for the existence of a kind of Hilbert-type multiple integral inequality with the non-homogeneous kernel and its applications, Journal of Inequalities and Applications (2017), 2017:316.

[26] D. M. XIN, B. C. YANG, A. Z. WANG, Equivalent property of a Hilbert-type integral inequality related to the beta function in the whole plane, Journal of Function Spaces, Volume 2018, Article ID2691816, 8 pages.

[27] Y. Hong, B. He, B. C. YAng, Necessary and Sufficient Conditions for the Validity of Hilbert Type Integral Inequalities with a Class of Quasi-Homogeneous Kernels and Its Application in Operator Theory, Journal of Mathematics Inequalities, 12(3)(2018), 777-788.

[28] J. C. KuAng, Applied inequalities, Shangdong Science and Technology Press, Jinan, China, 2004. 